\title{
Mechanism of A Lithiated Interlayer for Improving the Cycle Life of High Voltage Li-ion Batteries Using A Commercial Carbonate Electrolyte
}

Danyang Fan, ${ }^{\dagger}$ Dongsheng Lu, ${ }^{*},{ }^{\dagger}$ Siyong Wu,${ }^{\dagger}$ Ronghua Zeng, $,{ }^{\dagger} \mathrm{Jia} \mathrm{He},{ }^{\dagger}$

Dong Shu, ${ }^{\dagger}$ Yuepeng Cai ${ }^{\dagger, 末}$

† School of chemistry, South China Normal University, Guangzhou, 510006,

China;

$¥$ Guangzhou Key Laboratory of Materials for Energy Conversion and Storage, Guangzhou, 510006, China

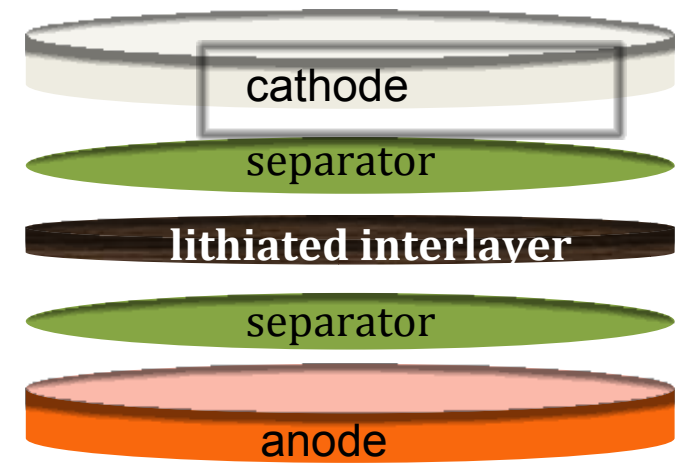

Figure S1. Schematic diagram of a LNMO/graphite full cell comprising a lithiated interlayer. 

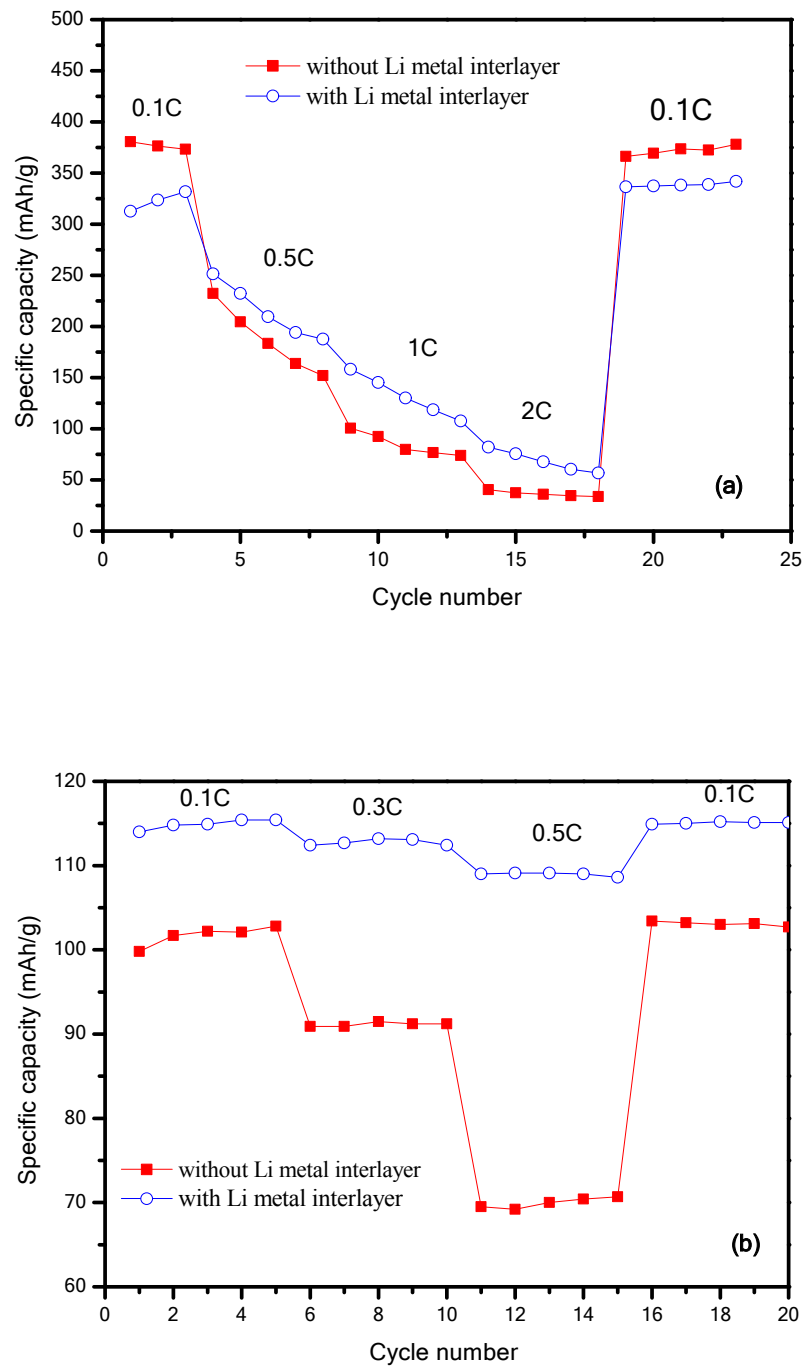

Figure S2. Rate capability of (a) Li/graphite cells and (b) Li/LNMO cells containing LNMO cathodes and graphite anodes extracted from the cycled LNMO/graphite cells in Figure. 1. 

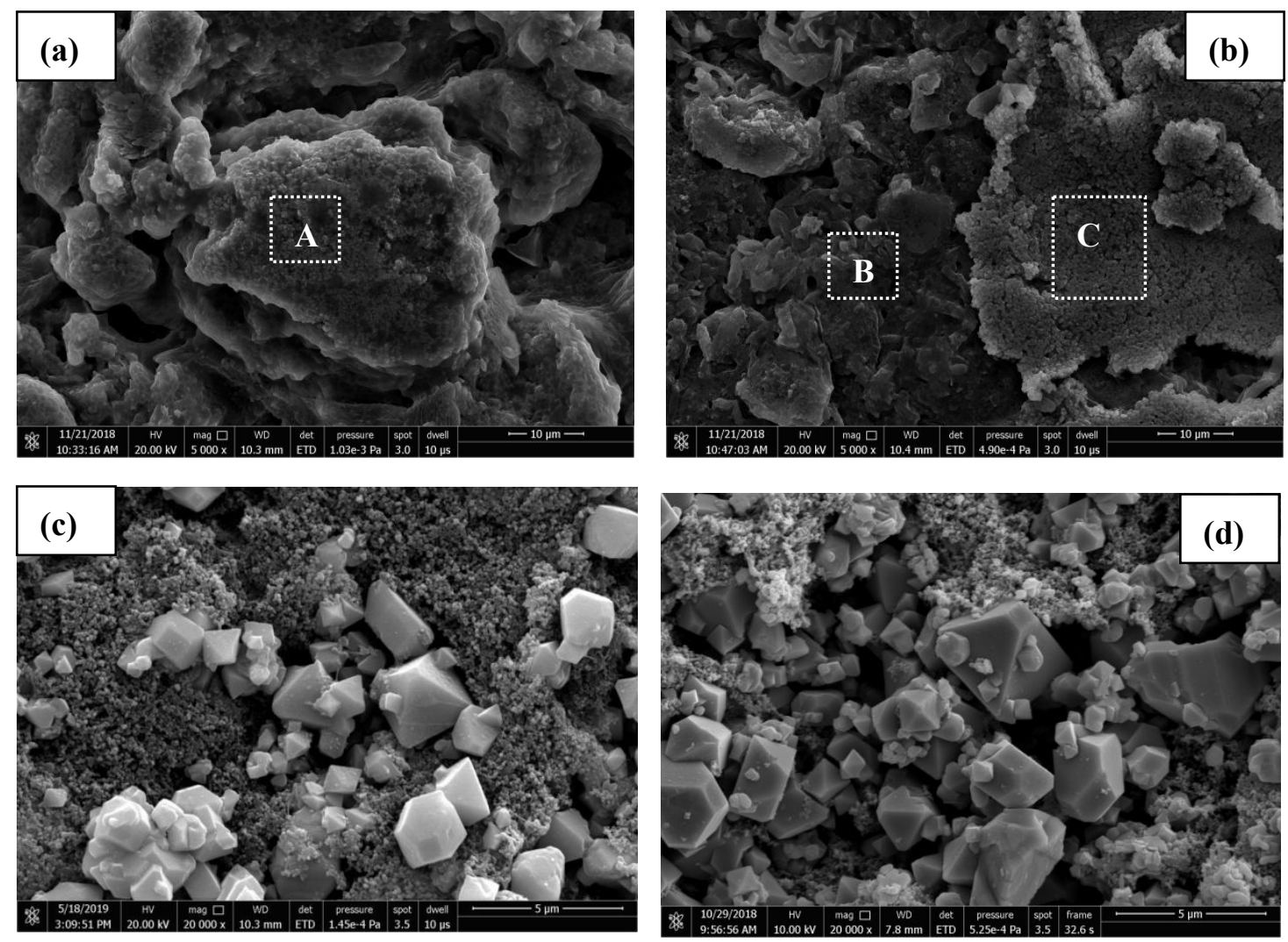

Figure S3. SEM images of (a-b) graphite anodes and (c-d) LNMO cathodes extracted from cycled LNMO/graphite cells applied the same cycling procedure as the cells in Figure.1. a and c: electrodes from the cell without Li metal interlayer; $\mathrm{b}$ and $\mathrm{d}$ : electrodes from the cell with Li metal interlayer 

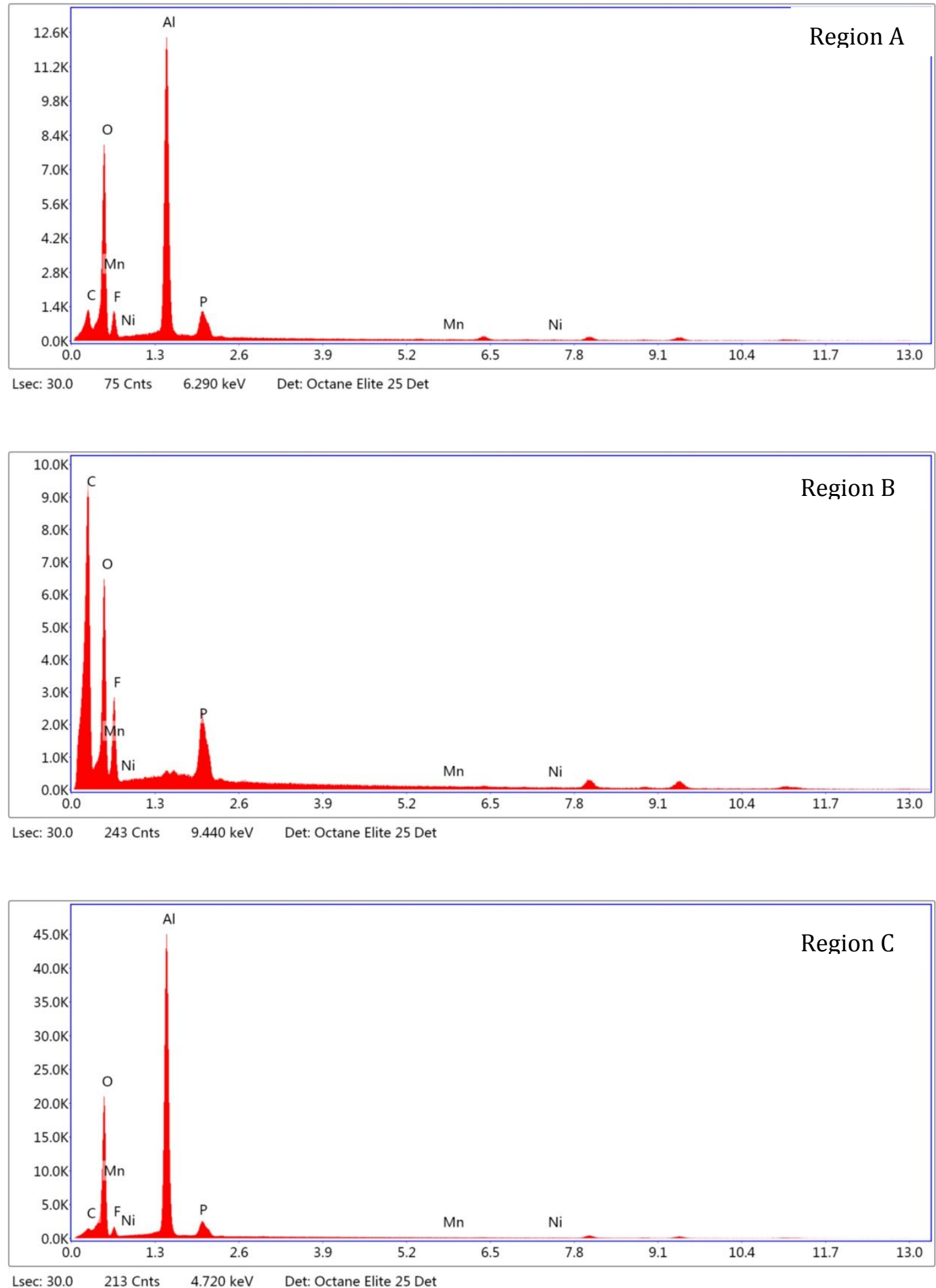

Figure S4. EDS analysis results of region A, B and C on the surface of the two graphite anodes extracted from cycled LNMO/graphite cells with and without Li interlayer. 

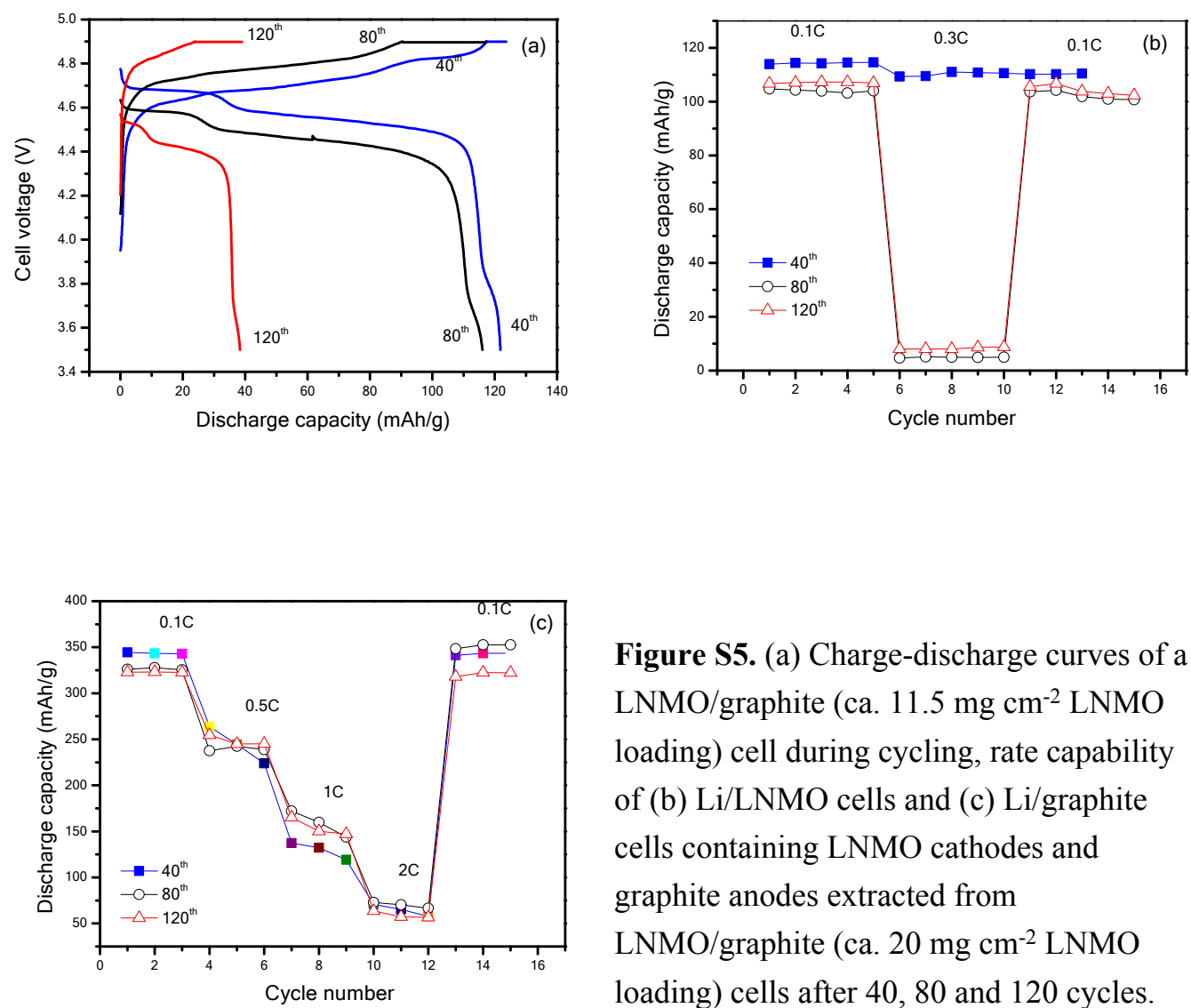

Figure S5. (a) Charge-discharge curves of a LNMO/graphite (ca. $11.5 \mathrm{mg} \mathrm{cm}^{-2}$ LNMO loading) cell during cycling, rate capability of (b) Li/LNMO cells and (c) Li/graphite cells containing LNMO cathodes and graphite anodes extracted from LNMO/graphite (ca. $20 \mathrm{mg} \mathrm{cm}^{-2}$ LNMO loading) cells after 40, 80 and 120 cycles.

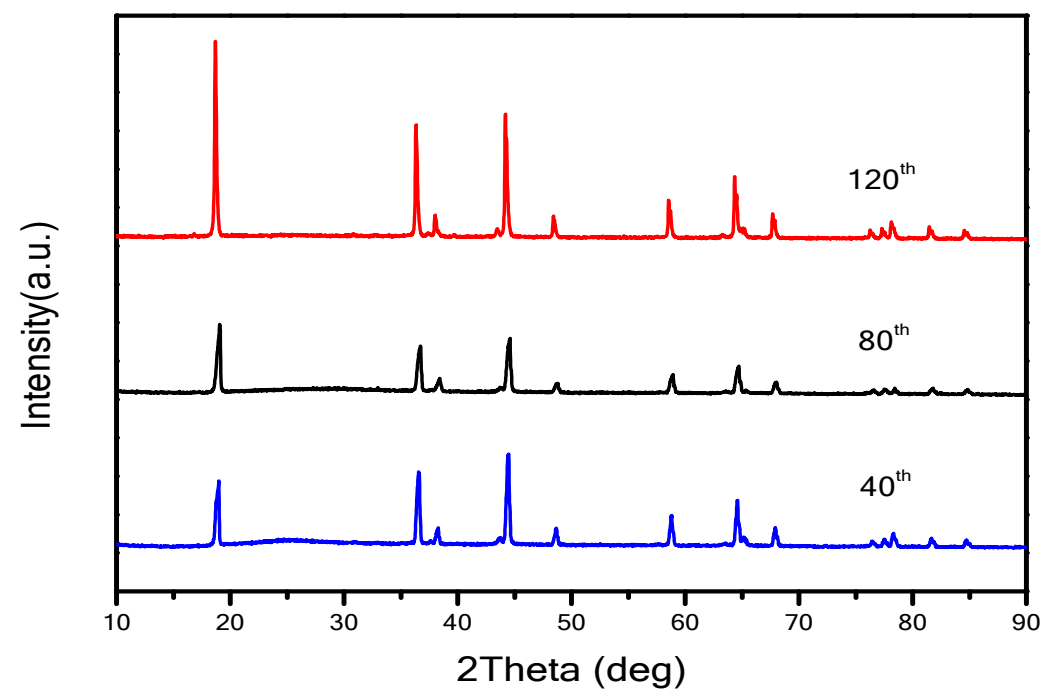

Figure S6. XRD patterns of LNMO cathodes extracted from LNMO/graphite (ca. $11.5 \mathrm{mg} \mathrm{cm}^{-2}$ LNMO loading) cells after 40, 80 and 120 cycles. 

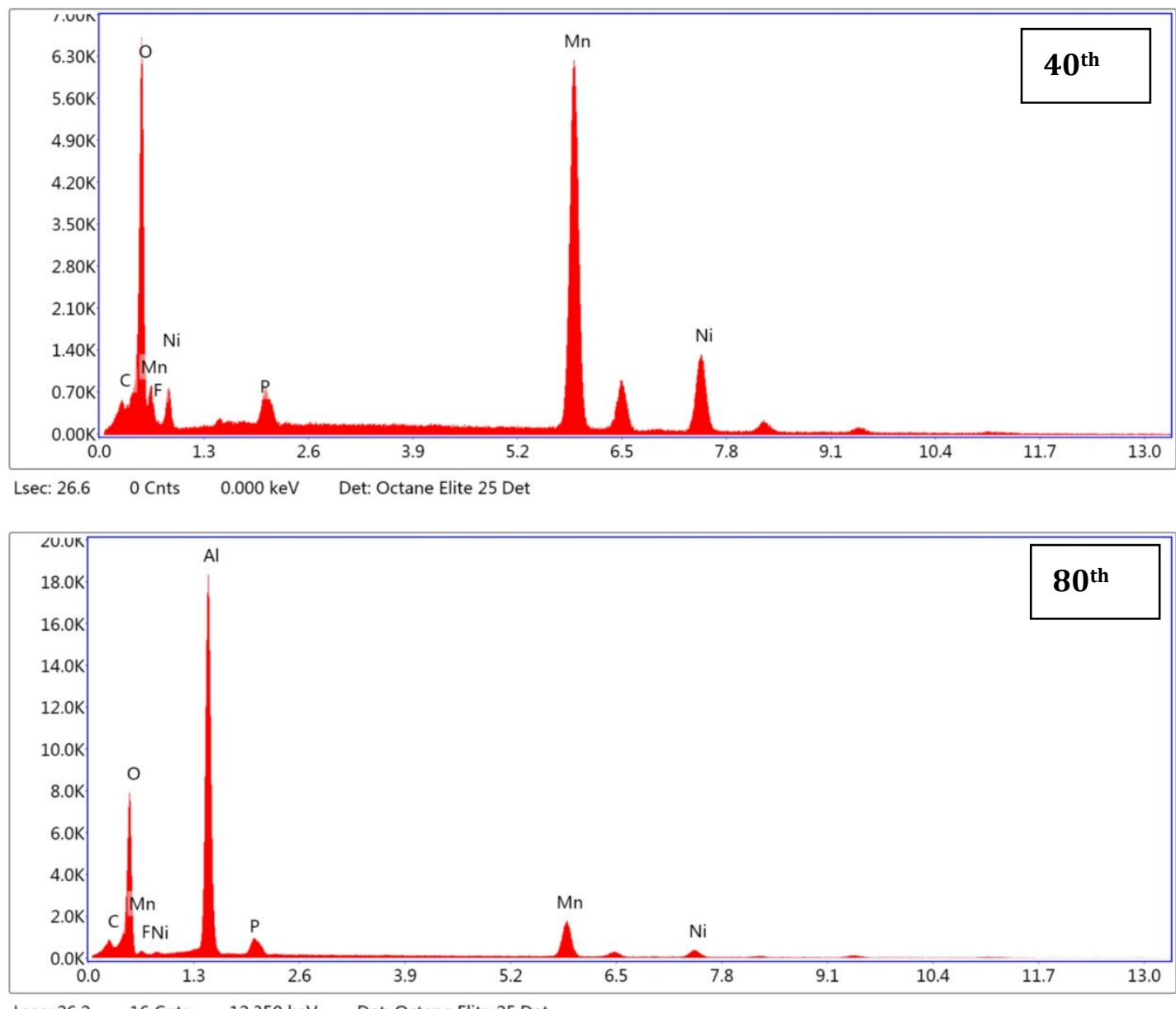

Lsec: $26.2 \quad 16$ Cnts $12.350 \mathrm{keV} \quad$ Det: Octane Elite 25 Det

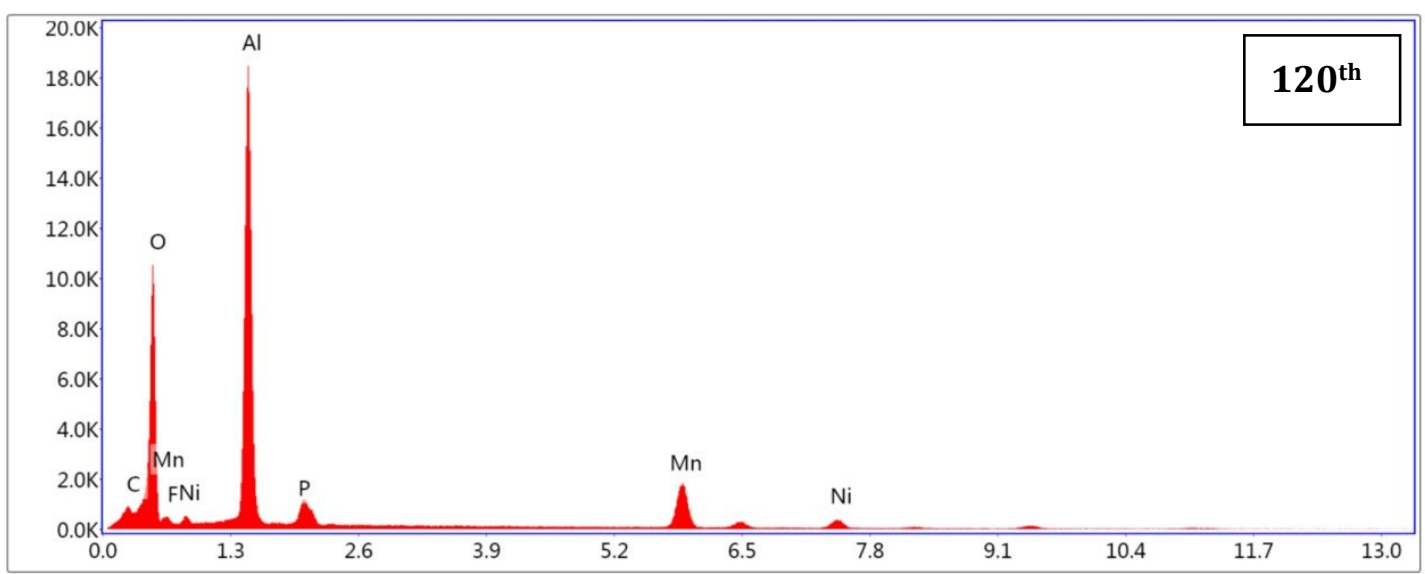

Lsec: $25.9 \quad 22$ Cnts $12.350 \mathrm{keV}$ Det: Octane Elite 25 Det

Figure S7. EDS analysis results of surface labeled regions of the three LNMO cathodes extracted from cycled LNMO/graphite cells with $\mathrm{Li}$ interlayers experiencing 40, 80 and 120 cycles. 

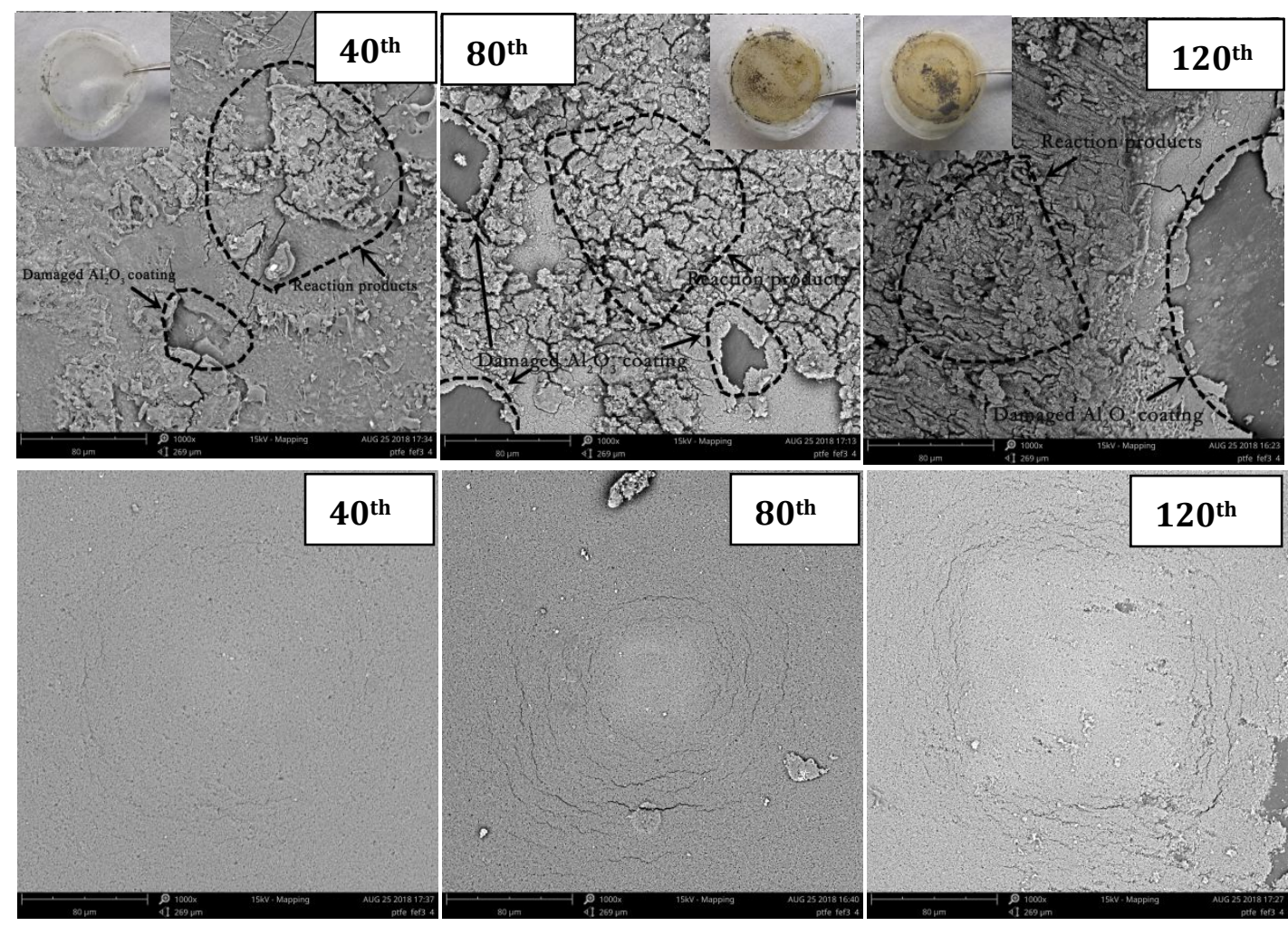

Figure S8. SEM images of two sides of PP separators extracted from LNMO/graphite (ca. 11.5 mg cm${ }^{-2}$ LNMO loading) cells after 40, 80 and 120 cycles. Insets: separator panoramas. Top: side facing Li metal interlayer. Bottom: side facing LNMO cathode. 
Text S1 Discussion of the role of Li interlayer in the full cell.

The failure mechanism of LNMO/graphite full cell and the role of Li interlayer are further discussed. When a LNMO/graphite full cell without Li interlayer is charged, besides the main reaction of $\mathrm{Li}^{+}$deserting from $\mathrm{LNMO}$ electrode and inserting into graphite electrode, the oxidation of electrolyte still exists on the cathode, and the reduction reactions of these oxidation products and the electrolyte occurs on the anode. The charging process can be expressed by the following formula according to Faraday's law:

$$
\begin{gathered}
(\mathrm{LNMO}) \quad Q^{c}=Q_{L i^{+} \text {desertion }}+Q_{\text {oxidation-of-electrolyte }}=m Q^{c}+n Q^{c} \quad(\mathrm{Eq} \mathrm{S} 1) \\
\left(\text { Graphite) } Q^{c}=Q_{L^{+} \text {insertion }}+Q_{\text {reduction-of-electrolyte }}+Q_{\text {reduction-of-oxidation- } \text { products }}\right. \\
=\alpha Q^{c}+\beta Q^{c}+\gamma Q^{c} \quad(\mathrm{Eq} \mathrm{S} 2)
\end{gathered}
$$

where $Q^{c}$ is charge capacity, $m$ and $n(0<m, n<1, m+n=1)$ are the capacity distribution coefficients of electrochemical desertion and oxidation of electrolyte on the cathode, respectively, $\alpha, \beta$ and $\gamma(0<\alpha, \beta, \gamma<1, \alpha+\beta+\gamma=1)$ are the capacity distribution coefficients of electrochemical insertion, reduction of electrolyte and oxidation products on the anode, respectively.

Similarly, when the cell is discharged, in addition to electrochemical insertion of $\mathrm{Li}^{+}$ in the cathode and electrochemical desertion of $\mathrm{Li}^{+}$from the anode, chemical oxidation reaction of electrolyte on the cathode and chemical reduction reaction of these oxidation products on the anode occur simultaneously, which causes the self-discharge of the full cell. The self-discharge reactions at two electrodes can be expressed as 


$$
\begin{gathered}
N i_{0.5} \mathrm{Mn}_{1.5} \mathrm{O}_{4}+x \mathrm{Li}^{+}+\text {Electrolyte } \rightarrow \mathrm{Li}_{x} \mathrm{Ni}_{0.5} \mathrm{Mn}_{1.5} \mathrm{O}_{4}+x \text { Electrolyte }^{+} \\
\mathrm{LiC}_{6}+x \text { Elecrolyte }^{+} \rightarrow L i_{1-x} \mathrm{C}_{6}+x \mathrm{Li}^{+}+E l \quad(\mathrm{Eq} \mathrm{S} 4) \\
\text { LiC }_{6}+x \text { Elecrolyte } \rightarrow L i_{1-x} \mathrm{C}_{6}+x L i^{+}+x \text { Elecrolyte }^{-} \text {(Eq S5) }
\end{gathered}
$$

where Electrolyte ${ }^{+}$and Electrolyte- represent the oxidation and reduction products of electrolyte, respectively, and El is reduction product of Electrolyte ${ }^{+}$. El and Electrolyte are different substances. So, the discharging process of the cell can be expressed as

$$
\begin{aligned}
& \text { (LNMO) } Q^{D}=Q_{\text {Electrochemical-insertion-of- } L i^{+}}=Q_{L i^{+} \text {desertion }}-Q_{\text {chemical-insertion-of-Li } i^{+}} \\
& =p m Q^{c}=m Q^{c}-q m Q^{c}
\end{aligned}
$$

$$
\text { (Graphite) } Q^{D}=Q_{\text {Electrochemical-desertion-of- } L i^{+}}
$$

$$
\begin{gathered}
=Q_{L^{+} \text {inesertion }}-\left(Q_{\text {reduction-of-electrolyte }}+Q_{\text {reduction-of-oxidation-products }}\right) \\
=e \alpha Q^{c}=\alpha Q^{c}-\left(f \alpha Q^{c}+g \alpha Q^{c}\right)
\end{gathered}
$$

where $Q^{D}$ is discharge capacity, $p$ and $q(0<p, q<1, p+q=1)$ are the capacity distribution coefficients of electrochemical $\mathrm{Li}^{+}$insertion and oxidation of electrolyte on the cathode, respectively, $e, f$ and $g(0<e, f, g<1, e+f+g=1)$ are the capacity distribution coefficients of electrochemical desertion, reduction of electrolyte and oxidation products on the anode, respectively.

Based on the above results, the charge efficiency $(\eta)$ of the cell is given by

$$
\begin{gathered}
\eta=\frac{Q^{D}}{Q^{C}} \times 100 \%=\frac{p m Q^{c}}{Q^{c}} \times 100 \%=\frac{e \alpha Q^{c}}{Q^{c}} \times 100 \% \\
=p m \times 100 \%=e \alpha \times 100 \% \quad(\text { Eq S } 8)
\end{gathered}
$$

In such a case, the value of $\eta$ depends only on the amount of electrochemical $\mathrm{Li}^{+}$ insertion and desertion at one electrode (cathode or anode). In other word, only by 
improving the charging efficiency of one of the electrodes can the charging efficiency of the full cell LNMO/graphite be improved. It is based on this idea that a lithiated interlayer is used to improve the cycle performance of LNMO/graphite cell.

For the full cell without Li interlayer, the oxidation products of the electrolyte on the LNMO electrode migrate to the negative electrode and are reduced, so $m$ is larger than $\alpha$, which means that only part of the $\mathrm{Li}^{+}$deserted from the cathode can be inserted into the anode during charging. According to Eq (S8), it can be deduced that $p$ is less than $e$. This result shows that $\mathrm{Li}$ in the anode cannot be completely electrochemically inserted into the cathode during discharging due to side react (Eq S3), (Eq S4) and (Eq S5). By analogy, both the charge capacity $\left(Q^{c}\right)$ and discharge capacity $\left(Q^{D}\right)$ of the full cell decrease with the increase of cycle number, which is consistent with the results shown in Figure 1.

When a $\mathrm{Li}$ interlayer is in the full cell, the oxidation products of the electrolyte that can be reduced at the anode will be reduced preferentially on the surface of the $\mathrm{Li}$ interlayer because potential of the $\mathrm{Li}$ interlayer $\left(0 \mathrm{~V}, \mathrm{vs} . \mathrm{Li}^{+} / \mathrm{Li}\right)$ is lower than

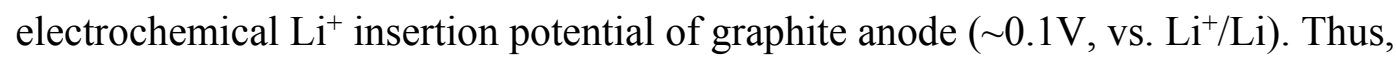
$\gamma=0$ in Eq (S2), the charging process of the graphite anode in the full cell can be expressed as

$$
Q^{c}=Q_{L^{+} \text {insertion }}+Q_{\text {reduction-of-electrolyte }}=\alpha Q^{c}+\beta Q^{c}
$$

Similarly, $g=0$ in Eq (S7), the discharge process of the anode is given by

$$
Q^{D}=Q_{\text {Electrochemical-desertion-of-Li+ }}=Q_{L i^{+} \text {inesertion }}-Q_{\text {reduction-of-electrolyte }}
$$




$$
=e \alpha Q^{c}=\alpha Q^{c}-f \alpha Q^{c}
$$

Because there is no effect of electrolyte oxidation products, a stable SEI film can form on the anode after several charge-discharge cycles, which will greatly inhibit the reduction of electrolyte. In other words, $\beta, f \rightarrow 0$ and $e, \alpha \rightarrow 1$, the discharge capacity $\left(Q^{D}\right)$ and charging efficiency $(\eta)$ of the full cell are obviously improved, which is consistent with the results of Figure 1.

The electrochemical oxidation of electrolyte can be considered as an irreversible process

$$
E l-e \rightarrow E l^{+}
$$

The current $(i)$ is related to the potential $(E)$ by the following equation: ${ }^{25}$

$$
i=n F A k_{b} C_{0} \exp \left[\frac{(1-\alpha) F E}{R T}\right]
$$

where $\mathrm{n}$ is number of electrons for the electrode reaction, $\mathrm{A}$ is electrode area, F, R and $\mathrm{T}$ are the Faraday constant, the gas constant, and temperature, respectively. $\alpha$ is transfer coefficient, $k_{b}$ is reaction rate constant, $C_{0}$ is concentration of reactant. $C_{0}$ can be considered invariant because the reactants EC and EMC are abundant in the electrolyte. Thus, the electrolyte oxidation reaction is completely controlled by the charge transfer step. It can be seen from Eq (S12) that the oxidation current increases with the increase in electrode area A and potential E, therefore the higher the LNMO loading the larger the electrode reaction area A of the cathode, leading to more electrolyte decomposition at high voltage. The SEI layer of Li interlayer is broken by a large number of oxidation products through the following reactions ${ }^{21-22}$

$$
\mathrm{Li}_{2} \mathrm{O}+2 \mathrm{HF} \rightarrow 2 \mathrm{LiF}+\mathrm{H}_{2} \mathrm{O} \quad(\mathrm{Eq} \mathrm{S} 13)
$$




$$
\begin{gathered}
\mathrm{Li}_{2} \mathrm{O}+\mathrm{CO}_{2} \rightarrow \mathrm{Li}_{2} \mathrm{CO}_{3} \quad(\mathrm{Eq} \mathrm{S} 14) \\
\mathrm{H}_{2} \mathrm{O}+\left(\mathrm{CH}_{2} \mathrm{OCO}_{2} \mathrm{Li}_{2} \rightarrow \mathrm{Li}_{2} \mathrm{CO}_{3}+\mathrm{CO}_{2}+\left(\mathrm{CH}_{2} \mathrm{OH}\right)_{2} \quad(\mathrm{Eq} \mathrm{S} 15)\right. \\
\mathrm{HF}+\left(\mathrm{CH}_{2} \mathrm{OCO}_{2} \mathrm{Li}\right)_{2} \rightarrow \mathrm{LiF}+\left(\mathrm{CH}_{2} \mathrm{COCO}_{2} \mathrm{H}\right)_{2} \quad(\mathrm{Eq} \mathrm{S} 16) \\
2 \mathrm{CH}_{3} \mathrm{OCO}_{2} \mathrm{Li}+\mathrm{H}_{2} \mathrm{O} \rightarrow \mathrm{Li}_{2} \mathrm{CO}_{3}+\mathrm{CO}_{2}+2 \mathrm{CH}_{3} \mathrm{OH} \quad(\mathrm{Eq} \mathrm{S} 17) \\
\mathrm{CH}_{3} \mathrm{OCO}_{2} \mathrm{Li}+\mathrm{HF} \rightarrow \mathrm{LiF}+\mathrm{CH}_{3} \mathrm{OCO}_{2} \mathrm{H} \quad(\mathrm{Eq} \mathrm{S} 18)
\end{gathered}
$$

where $\mathrm{Li}_{2} \mathrm{O},\left(\mathrm{CH}_{2} \mathrm{OCO}_{2} \mathrm{Li}\right)_{2}$ and $\mathrm{CH}_{3} \mathrm{OCO}_{2} \mathrm{Li}$ are the main components of the SEI

layer. Because a stable SEI films cannot be formed, the electrolyte (EC/EMC) will be continuously reduced and consumed on the surface of $\mathrm{Li}$ interlayer, which is especially significant for the full cell with high LNMO loadings. 